\title{
A (IN)CORPOREIDADE DO PROFESSOR EM TEMPOS DE PANDEMIA E EDUCAÇÃO À DISTÂNCIA
}

\author{
Kelly Cristina Brandão da Silva (UNICAMP)* \\ http://orcid.org/0000-0002-3512-1481 \\ Kelly Cristina Garcia de Macêdo Alcantara (USF)** \\ http://orcid.org/0000-0001-7525-8581
}

\begin{abstract}
RESUMO
0 artigo percorre alguns elementos tradicionais e ordinários do trabalho docente em sala de aula, no ensino presencial, para pensar os efeitos da educação remota, proposta em tempos de pandemia pelo coronavírus (SARS-CoV-2), em que escolas no mundo todo foram fechadas devido às medidas sanitárias de distanciamento físico, como forma de não interromper o ano letivo. Objetiva-se analisar, à luz da interlocução entre Educação e Psicanálise, os limites e impasses provocados pela educação à distância emergencial, a partir da discussão de algumas nuances referentes ao corpo, à presença e à temporalidade, os quais dão sustentação ao trabalho docente. Alguns desdobramentos a respeito da erotização da educação, da função da escola, da tradição e da transmissão são apresentados e iluminam tempos tão extraordinários.
\end{abstract}

Palavras-chave: Educação à distância emergencial. Psicanálise. Corpo. Presença. Temporalidade.

\section{ABSTRACT}

\section{THE TEACHER'S (UN)BODINESS IN TIMES OF PANDEMIC AND DISTANCE EDUCATION}

The article addresses some traditional and ordinary elements of classroom teaching, in face-to-face teaching, to think about the effects of remote education, proposed in times of pandemic by the coronavirus (SARS-CoV-2), in which schools worldwide were closed due to sanitary measures of physical distancing, as a way of not interrupting the school year. The objective is to analyze, in the

\footnotetext{
* Doutora em Educação (FEUSP). Docente do Departamento de Desenvolvimento Humano e Reabilitação da Faculdade de Ciências Médicas da Universidade Estadual de Campinas (UNICAMP) e do Programa de Pós-Graduação em Saúde, Interdisciplinaridade e Reabilitação (FCM/UNICAMP). Psicanalista e Psicóloga. Membro das redes: GT Psicanálise e Educação da Associação Nacional de Pesquisa e Pós-graduação em Psicologia (ANPEPP), Associação Brasileira de Saúde Mental (ABRASME) e Rede Universitária Internacional de Estudos Psicanalíticos Em Educação (RUEPSY). E-mail: kcbsilva@unicamp.br

** Doutoranda em Saúde, Interdisciplinaridade e Reabilitação pela Faculdade de Ciências Médicas da Universidade Estadual de Campinas (UNICAMP). Docente do curso de Graduação em Psicologia da Universidade São Francisco (USF). Psicóloga. Cofundadora do Instituto de Pesquisa e Estudos em Psicanálise nos Espaços Públicos (IPEP). Membro do grupo de Pesquisa Psicanálise, Política e Significante (PsiPoliS) do Instituto de Estudos da Linguagem da Universidade Estadual de Campinas (IEL/UNICAMP). Membro do Coletivo Estação Psicanálise. E-mail: ke.macedo@gmail.com
} 
light of the dialogue between Education and Psychoanalysis, the limits and impasses caused by emergency distance education, starting from the discussion of some nuances regarding the body, presence and temporality, which support the teaching work. Some developments regarding the erotization of education, the function of the school, the tradition and the transmission are presented and illuminate times of exception.

Keywords: Emergency distance education. Psychoanalysis. Body. Presence. Temporality.

\section{RESUMEN}

\section{LA (IN)CORPOREIDAD DEL PROFESOR EN TIEMPOS DE PANDEMIA Y EDUCACION A DISTANCIA}

El artículo cubre algunos elementos tradicionales y ordinarios de la enseñanza en la clase, en la enseñanza presencial, para pensar sobre los efectos de la educación remota, propuesta en tiempos de pandemia por el coronavirus (SARS-CoV-2), en el que las escuelas de todo el mundo han cerrado debido a medidas de salud de distancia física, como una forma de no interrumpir el año escolar. El objetivo es analizar, a la luz del diálogo entre Educación y Psicoanálisis, los límites y impases causados por la educación a distancia de emergencia, a partir de la discusión de algunos matices sobre el cuerpo, la presencia y la temporalidad, que apoyan el trabajo docente. Algunos desarrollos relacionados con la erotización de la educación, la función de la escuela, la tradición y la transmisión se presentan e iluminan tiempos tan extraordinarios.

Palabras clave: Educación a distancia de emergencia. Psicoanálisis. Cuerpo. Presencia. Temporalidad.

\section{Introdução ${ }^{1}$}

A pandemia deflagrada pelo coronavírus (SARS-CoV-2) impôs ao mundo globalizado uma ruptura em nossa vida ordinária, escancarando a desigualdade e as condições de vulnerabilidade social, causando morte, medo, insegurança e exigindo um trabalho de luto. Esse excesso de estranheza expõe nossa fragilidade humana e deveria nos alertar acerca da necessária humildade diante da magnitude dessa situação, cuja resposta exige solidariedade. Medidas básicas de higiene e distanciamento físico são considerados imprescindíveis para evitar a proliferação do vírus, apesar de despertarem sentimentos conflitantes de

1 Este artigo é um estudo teórico, resultado de pesquisa bibliográfica, e, por isso, não envolveu a obrigatoriedade de submissão ao comitê de ética. privação, castigo, perda, sacrifício e contrariedade. Até o momento, sem tratamento eficaz e específico para a Covid-19 e sem vacina, nosso enfrentamento tem sido paliativo e precário.

No campo da Educação, essa crise sanitária mundial impôs o fechamento das escolas. Segundo dados da Organização das Nações Unidas para a Educação, a Ciência e a Cultura (2020), estima-se que mais de 1,5 bilhão de estudantes foram afetados, o que corresponde a 91,4\% da população de estudantes do mundo, em 192 países. A utilização de plataformas de ensino à distância, a qual tem sido nomeada por várias instituições escolares e redes de ensino como "ensino remoto emergencial", tem sido cada vez mais frequente, dada a dimensão da pandemia. Em tempos extraordinários, atra- 
vessados por tantos afetos, sobressaltam os malabarismos dos professores, em um ofício já caracterizado por sua dimensão impossível, como nos dizia Freud (1969a).

0 relatório da Fundação Carlos Chagas (2020), em parceria com a Unesco, coletado entre o final de abril e início de maio de 2020 e respondido por mais de 14.000 docentes de todos os estados brasileiros, traz dados importantes sobre o atual momento na esfera da Educação. Com a exigência do distanciamento físico e início das práticas docentes realizadas de maneira remota, muitos fatores se elucidaram como parte dessa nova forma de ensinar, caracterizada pela excepcionalidade do contexto e que tem por objetivo "reduzir o prejuízo educacional e a preservação do direito à educação" (FUNDAÇÃO CARLOS CHAGAS, 2020, p. 1).

Para 65\% dos docentes que responderam ao questionário, houve mudança e aumento do trabalho docente realizado em suas casas, com atividades que incluem: suporte aos alunos e suas famílias, reuniões pedagógicas e cursos, novas ferramentas para ministrar e elaborar as aulas, responder a e-mails e mensagens de celular. Outro dado importante diz respeito à percepção dos professores sobre a realização das atividades propostas por seus alunos e o estado emocional deles: aproximadamente $50 \%$ dos docentes percebem que apenas uma parte dos alunos realiza as atividades e 53,8\% dizem notar aumento dos sintomas de ansiedade e depressão nas crianças e adolescentes (FUNDAÇÃO CARLOS CHAGAS, 2020).

Apesar das evidentes mudanças e transformações, há uma incessante exigência para que se mantenha "tudo normal" ou o mais próximo possível disso, o que revela uma negação da evidente suspensão da normalidade. Mais idealizado ainda tem sido o futuro, sintetizado na atual expressão "novo normal". É importante sublinhar que, no contexto brasileiro, de acordo com Ximenes e outros (2020), as políticas de ensino remoto têm caráter discriminatório e excludente, "em função da desigual distribuição dos prejuízos causados pela crise em relação a pobres, não-brancos, moradores da periferia e do campo, pessoas com deficiência e mulheres".

A abrupta transição e adoção de atividades não presenciais, apoiadas pelo uso de recursos oferecidos pelas Tecnologias de Informação e Comunicação (TIC), no campo da Educação, em tempos de pandemia, desnudam algumas questões que comumente não são discutidas, justamente porque ficavam eclipsadas no cotidiano supostamente natural e ordinário da docência. Tempos disruptivos, extraordinários, exigem um trabalho de luto e, a partir de Freud (1996b), compreende-se que é necessária a elaboração da perda. Afinal, o que eu perdi, naquilo que eu perdi?

Dessa forma, cabe retomarmos questões fundamentais, tal como, o que é uma aula? Disponibilizar aulas gravadas, sugerir leituras e promover, quando possível, aulas síncronas pode se configurar uma aula? Mesmo que todos os envolvidos, professores e alunos, tivessem pleno acesso à internet de qualidade, o que, sabemos, não é verdadeiro, quais as perdas estruturais nesse processo? Soluções meramente administrativas negligenciam toda a vivacidade de uma sala de aula, a qual pressupõe encontros, cheiros, gestos, olhares, vozes, dissensos, consensos e toda uma trama inapreensível pela tecnologia.

A partir dessa perspectiva, o presente trabalho objetiva analisar, à luz da interlocução entre Educação e Psicanálise, limites e impasses provocados pela educação à distância emergencial, a partir da discussão de algumas nuances referentes ao corpo, à presença e à temporalidade, os quais dão sustentação ao tradicional trabalho docente.

\section{0 tradicional trabalho docente: corpo, presença e temporalidade}

Primeiramente, cabe destacar que a acepção de "tradicional", neste trabalho, não se confunde com o uso corrente, nos meios escolares, 
relacionado à metodologia. Normalmente concebido como arcaico, fora do tempo e inútil ao mundo atual, tudo aquilo que é qualificado como "tradicional" é entendido, naturalmente, como ultrapassado. Deveríamos, nessa perspectiva, estar sempre à procura do novo e, por isso, a tecnologia é tão cobiçada, como se fosse a tradução perfeita da novidade.

Tradição, aqui, concerne ao conjunto de realizações históricas, costumes e práticas discursivas. Como bem explicita o sociólogo Castel (1994, p. 39), "a partilha de modos de vida enraizados em uma tradição, a participação em valores concretos que, através do investimento nas práticas comuns e na cumplicidade produzida pelo sentimento de pertencer a um mesmo meio, estruturam a vida cotidiana e dão sentido". De acordo com a filósofa Hannah Arendt (2009, p. 130), tradição não é sinônimo de passado, mas sim o "fio que nos guiou com segurança através dos vastos domínios do passado". Francisco (2007), alinhado à perspectiva arendtiana, destaca que esse "fio" ligaria as gerações entre si, a partir de um legado comum.

Lajonquière $(2010,2013)$ nos lembra que o conhecimento transmitido pelo professor traz consigo não apenas o conhecimento formal sobre as letras, os números e as demais ciências, mas também a marca da pertinência a uma tradição que inclui "uma cota de saber fazer com a vida" (LAJONQUIÉRE, 2013, p. 459). 0 professor, em seu ofício, ensina aquilo que aprendeu e que, por seu desejo, tenta transmitir, afinal, "educar é transmitir marcas simbólicas que possibilitem à criança conquistar para si um lugar numa história, mais ou menos familiar, e, dessa forma, poder se lançar às empresas do desejo" (LAJONQUIÉRE, 2010, p. 62). 0 conhecimento que partilha carrega a contradição de ser dele, embora não lhe pertença, pois aquilo que se aprende nos é sempre emprestado de alguma tradição.

Memória e educação estão entrelaçadas nessa perspectiva de tradição. Contudo, como nos diz Souza (1997), o Brasil é um país que tem, por vezes, uma relação hostil com sua memória e, a partir de um ideal positivista, de uma suposta linearidade temporal, mantém-se um imperativo em direção ao progresso. 0 tempo que interessa é o futuro, guardião de uma promessa de prosperidade, sobre a qual pouco se sabe e em nome da qual tudo se faz em um presente que se esvai rapidamente. Em tempos de pandemia, em que há uma suspensão do tempo, em uma espécie de presente perpétuo, talvez seja relevante refletir sobre o "fio" que nos liga ao passado, a fim de iluminar nossas atuais escolhas.

A escola, apesar de todas as transformações pelas quais passou e tem passado ao longo dos anos, se constitui como lugar de transmissão e se mantém como tal, como lembrado por Rahme (2012). Todavia, há impasses importantes nessa relação entre a tradição da escola e as demandas provenientes de diferentes esferas do corpus social:

[...] é possível observar a existência de uma expectativa de que ela [a escola] contribua, como instituição, para tornar menos segregadora isso a que chamamos de coletividade. Entretanto, se considerarmos que vivenciamos na atualidade uma hegemonia da lógica dos mercados comuns, materializados pelo discurso do mestre em sua versão capitalista, como apreender o que seria mais peculiar à relação laço social educação hoje? (RAHME, 2012, p. 46).

Apesar dos impasses e transformações, é possível considerar que o trabalho docente, presencial, tem um lastro tradicional. A imbricação entre corpo, presença e temporalidade, na Educação, construída por muitos e transmitida através das gerações, constitui a memória do tão bem nomeado corpo docente e pode ser explicitada a partir de alguns pressupostos psicanalíticos.

O corpo, para a Psicanálise, não é o da Biologia. Trata-se de um corpo atravessado pela linguagem, erógeno, marcado pelo encontro com o Outro. Silva (2019, p. 159) sublinha que esse corpo é afetado, "um corpo erógeno que emerge do corpo biológico. E não há psiquismo que se constitua fora da relação entre um corpo 
erotizado e que erotiza outro". Freud (1969b) já indicava que a relação de uma criança com seus cuidadores é permeada por sedução e excitação sexual.

Nesse processo de libidinização e constituição psíquica, dois elementos merecem destaque e são imprescindíveis na discussão sobre o trabalho docente, quais sejam, o olhar e a voz, discutidos por Lacan (1964/1979) a partir dos conceitos de pulsão escópica e pulsão invocante. Olhar e voz, na tradição lacaniana, são entendidos além dos órgãos sensoriais da visão e da audição. Em relação ao olhar, apresentam-se múltiplas dimensões, como olhar, ser olhado, provocar o olhar e esconder-se. No que concerne à voz, em que ouvido e boca estão implicados, há as dimensões do escutar, ser escutado, provocar a escuta, falar e ser falado.

$\mathrm{Na}$ introdução do infans na cultura, os cuidadores supõem um sujeito no pequeno ser, a partir de uma ilusão antecipadora, a qual inaugura algo que ainda não estava lá, mas que só pôde advir devido a uma suposição. 0 desejo do cuidador convoca o sujeito, através do toque, da voz e do olhar, em um espaço compartilhado, em uma temporalidade síncrona.

Na perspectiva psicanalítica lacaniana, é no campo do Outro que o sujeito se constitui, efeito da ação da linguagem, a partir de um investimento libidinal. É necessário alienar-se no desejo e nas palavras de um Outro para poder ter existência simbólica:

[...] o sujeito não cria seu discurso, mas é causado por ele, e existe apenas por causa do discurso e da linguagem. Só pode manifestar-se porque encontra na linguagem um substrato, um apoio, uma forma que o cria e permite seu advento. 0 sujeito precisa da palavra para existir e para dizer-se. (KUPFER, 2010, p. 269).

Inicialmente, a linguagem vai habitá-lo, marcá-lo e só depois o bebê terá a ilusão de dominá-la, de tê-la "adquirido". Ao se dar conta de que o Outro não é tão absoluto, que algo lhe falta, o pequeno ser começará a se indagar sobre o desejo. Entretanto, apesar da necessária separação, a alienação é estrutural e deixa marcas. Uma prova disso é a formação do eu, o qual se constitui na base do desconhecimento, nesta alienação ao olhar e às palavras do $\mathrm{Ou}$ tro, bem como em uma colagem imaginária à ilusão de completude que a imagem especular fornece. Destaca-se ainda que essas operações de causação do sujeito - alienação e separação - somente têm efeito a partir de uma alternância entre presença e ausência do cuidador (KUPFER et al., 2009).

No tradicional trabalho docente, presencial, todos esses elementos que nos constituem psiquicamente estão imbricados. Apesar da teorização da pedagogia contemporânea, como bem salienta Voltolini (2019), deserotizar a relação entre professores e alunos e também a relação com o próprio conhecimento, reduzido ao seu aspecto utilitarista, não é possível, tampouco desejável, apagar o Eros da educação. Como sublinha esse autor, "O amor, enquanto Eros, não é, portanto, um fator superficial na relação pedagógica, contingente." (VOLTOLINI, 2019, p. 380). No valor imensurável da transmissão desejosa do professor se inscreve a questão: o Outro, o que quer de mim? Os conhecimentos formais vão preenchendo o lugar dos não-saberes, mas é $o$ ato educativo que lança o enigma sobre o desejo do Outro, que carrega em si o impossível de responder, assim como é impossível de findá-lo, como sublinha Lajonquière (2013).

\section{Educação em tempos de pandemia: urgente, mas sem pressa}

Antes de discutir alguns limites e impasses do chamado ensino remoto emergencial, cabe salientar, a partir das argumentações de França Filho, Antunes e Couto (2020, p. 28), que é "incabível tentar estabelecer uma distinção real em termos teóricos, entre a EaD e o ensino remoto, pois o segundo é simplesmente uma versão do primeiro realizada de forma bruta sem o romantismo do primeiro". De acordo com 
esses autores, há uma tentativa, a qual não se sustenta, de diferenciar a educação à distância (EaD) do atual ensino remoto, afinal, este se apresenta como uma prática improvisada, sem planejamento prévio, com o objetivo de atender às demandas imediatas de educação, em razão do fechamento das escolas causado pela pandemia.

Os setores críticos à associação entre a atual prática emergencial e a EaD argumentam que esta última obedece a uma organização curricular prévia, com a elaboração de materiais didáticos adequados, capaz de atender às necessidades educacionais do estudante à distância. França Filho, Antunes e Couto (2020) salientam, de forma contundente, que essa oposição é falsa, mistificadora e apresenta-se como uma tática de defesa dos favoráveis à EaD. É necessária muita atenção, pois é muito provável, no horizonte pós-pandemia, que, "aproveitando-se desta crise, capital e Estado apresentarão como tábua de salvação nas ruínas do retorno à normalidade o seguinte receituário: o EaD, o homeschooling e, sobretudo, o acesso à educação via vouchers" (FRANÇA FILHO; ANTUNES; COUTO, 2020, p. 29).

Ciente desse alerta e das possíveis implicações nas políticas públicas, este trabalho privilegia a expressão "educação à distância emergencial", tanto para marcar as semelhanças entre a atual atividade remota docente com a EaD, quanto para sublinhar o caráter de urgência instaurado pela pandemia. Conforme já indica o título dessa seção, urgente, mas sem pressa, visto que a Educação, como bem público, é um direito humano fundamental e um dever do Estado. Não obstante, o ineditismo deflagrado pela pandemia exige desaceleração, cautela e acordos coletivos, a fim de não exacerbar as profundas desigualdades que já aconteciam no campo educacional; provocar discriminação e exclusão da parcela mais vulnerável da sociedade e, no caso específico da discussão deste trabalho, negligenciar as diferenças estruturais e subjetivas entre a atividade docente presencial e à distância.
A fim de compreender os efeitos da repentina interrupção das aulas presenciais nas escolas e a consequente oferta de aulas em plataformas virtuais, é interessante apresentar algumas proposições do arquiteto e filósofo francês Paul Virilio (1993), elaboradas muito antes da pandemia, acerca das transformações na percepção de tempo dessa nossa era teleinformatizada. Esse autor discute que no ciberespaço há um apagamento da separação entre o próximo e o distante, além de superexposição, sem ocultação entre público e privado.

Nas palavras de Virilio (1993, p. 10-11), no ciberespaço "privado de limites objetivos, o elemento arquitetônico passa a estar à deriva, a flutuar em um éter eletrônico desprovido de dimensões espaciais, mas inscrito na temporalidade única de uma difusão instantânea". 0 tempo, nesta perspectiva, é um presente permanente, "ao tempo que passa da cronologia e da história sucede portanto um tempo que se expõe instantaneamente" (VIRILIO, 1993, p. 10, grifo do autor).

Cabe aqui sublinhar a mudança, apontada pelo autor, entre o tempo que passa e o tempo que se expõe. Essa transformação não é sem consequências no campo educativo, principalmente para crianças pequenas, ainda em processo de constituição psíquica. Na infância, o tempo que passa é imprescindível para a própria construção da noção de tempo. Um "presente permanente", o qual se expõe instantaneamente, dificulta a instauração das operações psíquicas constituintes do sujeito.

É importante destacar que esse fenômeno das intoxicações eletrônicas na infância (BAPTISTA; JERUSALINSKY, 2017) não é recente, mas se exacerba na atualidade da pandemia e ganha ainda mais impulso na modalidade de educação à distância. Normalmente, a escola, 0 lugar tradicional da educação básica, servia de anteparo ao ciberespaço. Atualmente, a escola, justamente o lugar dos encontros presenciais, que se interpõe, de acordo com Arendt (2005, p. 45), entre a "vida resguardada do lar" e a "impiedosa vulnerabilidade da vida na polis", 
entre o privado e o público, cede espaço para a tela, no ambiente doméstico.

Em tempos de aulas virtuais, uma pergunta parece sintetizar a difícil apreensão humana dessa novidade: Afinal, onde nos encontramos, quando nos encontramos na tela? Qual seria esse espaço não simultâneo, tão inédito no campo educacional, principalmente em se tratando de educação básica? Esse novo território não se configura exatamente como um lugar - no sentido antropológico - mas uma flutuação, sem limites objetivos, como bem caracteriza Virilio (1993). Trata-se de habitar um espaço, mediatizado pela tela, em que o distanciamento e o achatamento dos corpos impõem novas configurações e invenções. Corpos que permanecem sentados e recortados, visto que somente os rostos aparecem.

Para o professor, tão acostumado a estar na cena escolar, na sala de aula, em posição privilegiada e central, como um ator no palco, a educação à distância emergencial exige uma modificação profunda, imaginária. Se antes, seu olhar e voz convocavam os alunos, os quais também respondiam - de forma interessada ou não - através de olhares e vozes, em tempos de pandemia o professor se encontra, muitas vezes, sem recursos para saber quais seriam os indícios virtuais de engajamento, cansaço ou indiferença dos alunos. Isso se verifica tanto em aulas síncronas quanto em aulas assíncronas. Nas primeiras, a qualidade da conexão impõe aos alunos fechamento de câmeras e microfones. Assim, o professor tem diante de si uma tela sem rostos. Os corpos, já tão apagados nessa modalidade à distância, desaparecem. Inclusive o silêncio dos alunos adquire um novo significado. Desinteresse ou falha da conexão da internet? Por isso mesmo é tão comum, em aulas síncronas, as frequentes perguntas dos professores: Vocês estão me ouvindo? Vocês estão me vendo? Interrogações que mal escondem o desejo de garantir a própria existência.

Voltolini (2007a, p. 125), ao analisar as relações entre corpo, imagem, presença e distância na modalidade EaD, enfatiza a importância nar- císica da imagem corporal, tanto no processo de constituição psíquica quanto como resto infantil nos adultos:

Para o homem, seu corpo, a partir de um momento inaugural e daí para sempre, restaria comprometido com a imagem unificada dele, capturada no espelhamento que o outro que se ocupa do infans lhe possibilita quando simplesmente olha para ele como um sujeito. Fascinado com a própria imagem retornada deste espelho o humano não poderá jamais, ao longo de toda sua vida, deixar de apaixonar-se por ela, a ponto de que em todas as suas futuras relações estará, feito Narciso, 'condenado' a vê-la aparecer como uma sombra que media a relação com o outro.

Outra alteração que se destaca, com o uso das plataformas virtuais, em aulas síncronas, é o inusitado fenômeno de ver a si mesmo, através da tela. Nos encontros presenciais, não vemos nossos rostos, a não ser pelo olhar do outro. Quais os efeitos dessa permanência constante da nossa imagem? Tal como Narciso, nosso destino seria sucumbir?! Ainda a respeito da pulsão escópica, é necessário sublinhar outro fator bem perturbador para os docentes, qual seja, a presença de outras pessoas no ambiente virtual. Pais de alunos, familiares, coordenadores e tantos outros que podem acompanhar as aulas, sem serem vistos, frequentemente assumindo uma postura de controle e vigilância. Quem me olha? Como me olha? Quando me olha? Olhares múltiplos, perturbadores e, por vezes, persecutórios. Além disso, o contato visual, garantia mínima de estabelecimento de vínculo, não é possível através das plataformas virtuais. Para que os olhares se encontrem, no ciberespaço, os olhos têm que se direcionar para a câmera. Difícil sustentar tal laço, tão inusitado.

Esses excessos pulsionais relacionados ao exercício da docência no mundo virtual exigem do professor, em tempos de pandemia, uma necessária ampliação da jornada de trabalho a fim de dar conta da súbita novidade. Ademais, a urgência imposta pelo lema "a educação não pode parar", em muitas instituições e redes de ensino, obrigaram à rápida compreensão 
de diversas ferramentas tecnológicas, novo vocabulário e novas funções, como a de professor-tutor dos pais dos alunos, os quais foram severamente afetados pela nova condição de transformar-se em professores dos filhos, no ambiente doméstico.

Aliás, a função de fronteira que cabia à escola, a qual separava o ambiente privado do professor, sua intimidade, da exposição da sala de aula, se esvai em tempos de home office. A onipresença das suas origens, agora materializada na imagem das suas casas, com seus barulhos, seus objetos, seus personagens, suas convocações e suas limitações insiste e persiste, expondo ao público aquilo que antes ficava restrito à esfera privada. A nova tarefa docente, precária diante de tantos desafios, sem a tão ilusória e necessária cena de aprendizagem, em que alunos e professores usufruíam e compartilhavam o conhecido e tradicional tempo e espaço escolar, impõe muita sobrecarga de trabalho.

Diante dessa perspectiva, é importante destacar a publicação, em 17 de junho de 2020, da Nota Técnica - GT COVID 19 - 11/2020 do Ministério Público do Trabalho (BRASIL, 2020), a qual dispõe sobre a atuação do MPT e insta que estabelecimentos de ensino adotem vinte e seis medidas para garantir a proteção à saúde e aos demais direitos fundamentais de professoras e professores quanto ao trabalho por meio de plataformas virtuais, trabalho remoto e/ou em home office durante o período da pandemia da doença infecciosa COVID-19. A maior parte das recomendações está relacionada à jornada, direitos autorais e condições de trabalho. 0 documento é válido para todo o território nacional.

Uma das medidas listadas pelo MPT merece destaque, pois auxilia na discussão do presente trabalho:

ADOTAR modelos de etiqueta digital em que se oriente alunas(os), responsáveis, supervisoras(es) e diretoras(es), com especificação de horários para atendimento virtual da demanda, assegurando os repousos legais, $o$ direito à des- conexão do corpo docente e a compatibilidade entre a vida familiar e profissional. (BRASIL, 2020, p. 7, grifo nosso).

A palavra conexão admite vários significados: ligação de uma coisa com outra; união; relação de dependência e ligação entre computadores e dispositivos para que dados sejam transferidos. 0 direito à desconexão, preconizado pelo MPT, indica a exaustão provocada pela modalidade virtual. Novidade abrupta para todos os envolvidos, sem precedentes, sem história e sem tradição. A educação à distância emergencial impõe uma nova linguagem, outra experiência cognitiva e subjetiva e impossibilita a mera transposição das tradicionais atividades presenciais no mundo virtual. Como bem indica Virilio (1993, p. 11, grifo do autor), no ciberespaço, "a chegada suplanta a partida: tudo 'chega' sem que seja preciso partir". Justamente por isso, o direito à desconexão é tão imprescindível.

Em uma perspectiva psicanalítica, conexão pode ser entendida como transferência, conceito freudiano elaborado a partir de obstáculos à técnica da interpretação. Como bem salienta Voltolini (2007a, p. 134, grifo nosso), "Foi se dando conta de que 'sua presença' na cena do outro havia lhe passado inadvertida e que esta desconsideração lhe custava caro para a direção da cura, que Freud formula a importância de se levar em consideração a transferência". Essa temática interessa sobremaneira à Educação, visto que os encontros entre professores e alunos, assim como todos os encontros humanos, são permeados pelo amor de transferência. Mais uma vez, é preciso sublinhar a impossibilidade estrutural de se deserotizar o campo educacional. Destaca-se que o uso da palavra encontro, no lugar da alardeada expressão relação professor-aluno, permite enfatizar "o caráter vivo, concreto, imprevisível e improvisado característico do que se passa entre humanos" (VOLTOLINI, 2007a, p. 135).

Na tradição psicanalítica, a dialética presença-ausência, como foi ilustrado por Freud (1969b) com o jogo do fort-da, é uma expe- 
riência constitutiva para o sujeito. Figueiredo (2009, p. 130), a partir de um estudo sobre o cuidado, afirma que "a condução de um processo de psicanálise requer do analista a capacidade de manter-se, simultaneamente, como presença implicada presença reservada". 0 autor critica tanto as posições de neutralidade, indiferença e silêncio, quanto a excessiva implicação, que pode se tornar exercício de domínio. A presença do analista, para o autor, situa-se em um lugar intermediário entre presença e ausência, de modo que lhe permita fazer as funções de acolhimento, sustentação e reconhecimento.

A partir dessa perspectiva psicanalítica e refletindo acerca da importância dessa discussão no campo do EaD, Silva (2010, p. 65, grifo do autor) sublinha que

[...] a noção de presença pode ser pensada no plural, como presenças, o que nos indica que não há um único modus de presença nem uma presença ideal. As presenças podem variar em diferentes possibilidades, conforme as necessidades e contingências da vida que, como tal, incidem sobre a transferência.

Muito antes da pandemia, essa autora já alertava, que "o índice de evasão em cursos via EaD costuma ser alto, o que nos faz pensar que o trabalho com o estabelecimento e a sustentação da transferência é um aspecto importante nesse contexto" (SILVA, 2010, p. 62).

Ao tratar da educação à distância emergencial, em tempos de pandemia, também não se pode desconsiderar esse elemento estrutural. As plataformas online compradas pelas escolas particulares possibilitam, apesar de inúmeras dificuldades, o "estar junto virtual", tal como propõe Valente (2009), por meio da imagem e da voz em sincronicidade temporal. Esses encontros, ainda que virtuais, podem facilitar a emergência ou a sustentação da transferência. Todavia, a substituição total das atividades escolares presenciais por aulas assíncronas ou atividades escritas negligencia o papel fundamental da transferência nos encontros humanos.
Tal substituição tem se verificado, frequentemente, em escolas públicas. As atividades enviadas para que o aluno faça em casa, ajudado por seus familiares ou cuidadores, retornam no papel, opaco, o qual não diz e não ouve sobre as particularidades do encontro entre alunos, professores e o conhecimento. Acreditar que a presença do professor não importa é reduzi-lo ao papel de mero portador de informações. Freud (1976a), em seu texto de 1914, Algumas reflexões sobre a Psicologia Escolar, refere a importância do professor para os efeitos da transmissão do conteúdo escolar: "é difícil dizer se o que exerceu mais influência sobre nós e teve importância maior foi a nossa preocupação pelas ciências que nos eram ensinadas, ou pela personalidade de nossos mestres" (FREUD, 1976a, p. 286).

Em tempos de abismo entre a educação pública e a educação privada, os efeitos da pandemia, os quais transformaram em remoto, à distância, o trabalho do professor, escancaram nossas velhas desigualdades e provocam novas situações de discriminação e exclusão.

\section{Do ideal ao emergencial: afinal, qual é o sentido da Educação?}

Silva (2016) aponta o quanto o discurso pedagógico hegemônico se fundamenta em um ideal de simetria, largamente difundido, entre ensino/aprendizagem e professor/aluno. Nessa perspectiva, quaisquer percalços na empreitada educativa são entendidos como um problema de gestão, facilmente equacionados com novas metas, planejamento e avaliação dos resultados. Em um campo marcadamente idealizado, como a Educação, o que se desvela, muitas vezes à revelia, é justamente o oposto, ou seja, o fracasso.

Voltolini (2001) sublinha a idealização pedagógica, a partir da exigência de alta performance, a qual mal esconde suas ambições capitalistas, tanto do desempenho do professor quanto do aluno, que também deveria desen- 
volver plenamente suas capacidades. "O que ocorre, todavia, é um transbordamento, um retorno de uma verdade na falha de um saber, o que nos leva a perceber que a mestria falha, como, aliás, qualquer discurso, em sua pretensão totalizadora" (VOLTOLINI, 2001, p. 110). Esse autor ainda indica a face maníaca dessa exigência de maximizar o desempenho rumo a um ideal vago:

Assim como é próprio do capitalismo a verdade que retorna é a que aponta para uma relação assim formalizada, na qual num polo temos alguém que deve ser 'maximamente eficaz', que tudo deve fazer para cumprir o ideal (o professor), e no outro temos alguém que deve receber o 'máximo' para que se desenvolva o 'máximo' que puder (note-se que o que define esses máximos nunca é explicitado, ou o é em termos vagos, de operacionalidade difícil). Pois bem, a verdade que retorna é a que aponta para o fato de que numa relação assim formalizada uma formação depressiva é bastante esperada, já que a palavra de ordem é maníaca. (VOLTOLINI, 2001, p. 108-109, grifo do autor).

É importante sublinhar, de acordo com Lajonquière (2013, p. 460), que "Em todo ato educativo há embutido uma cota de dever ser ideal", a qual se inscreve na ordem imaginária e simbólica. Entretanto, como uma tarefa eminentemente humana, a Educação convive, paradoxalmente, com a impossibilidade de sua realização, visto que nunca alcança a totalidade da sua intenção, também não-toda. A docência carrega em si o paradoxo da sujeição ao discurso do Outro. Aquele que ensina é, também, aquele que testemunha o impossível desse fazer, pela castração que nos diz sempre da nossa marca constituinte, a falta.

Marcar a dimensão impossível da Educação não significa assumir uma atitude de impotência. Voltolini (2011, p. 25) compreende a afirmação freudiana sobre a impossibilidade de educar a partir da lógica filosófica, sublinhando que a "impossibilidade em questão não alude a um plano prático de execução de uma determinada proposta educativa”, já que "impossível não quer dizer 'inexequível', apontando, antes, para um inalcançável estrutural".

Um alerta lacaniano sintetiza da seguinte forma essa impossibilidade estrutural: "Você pode saber o que disse, mas nunca o que o outro escutou". Mesmo aquilo que dizemos não é passível de um saber total. Há sempre algo que escapa, inconsciente. Precisamente por isso, em vez do termo ensino, muito comum nos meios escolares, na tradição da interlocução entre Psicanálise e Educação, o termo privilegiado é transmissão.

A educação está implicada com a "transmissão, no campo da palavra e da linguagem, dos conhecimentos mais variados, bem como também do desejo inconsciente que nos humaniza." (LAJONQUIÈRE, 2013, p. 461). Diante dessa perspectiva, Silva (2016, p. 112-113, grifo do autor) destaca que, na transmissão, entra em cena o laborioso trabalho de apropriação, sendo que a

[...] escolha pelo termo transmissão sublinha que alguma coisa escapará nesse processo. Apesar de todo empenho (ou não) de quem está na posição de educar, não há como determinar $a$ priori o que será aprendido. Lembramos aqui uma citação de Goethe, feita por Freud: 'O que herdaste de teus pais, adquire-o para que o possuas'.

Freud (1996a), em nome próprio, testemunha a desproporção estrutural entre o ensinar e o aprender e afirma que recebera ideias de três mestres, que, mais tarde, recusariam admitir os créditos referentes a elas.

A ideia pela qual eu estava me tornando responsável de modo algum se originou em mim. Forame comunicada por três pessoas cujos pontos de vista tinham merecido meu mais profundo respeito - o próprio Breuer, Charcot e Chrobak, o ginecologista da universidade, talvez o mais eminente de todos os nossos médicos de Viena. Esses três homens me tinham transmitido um conhecimento, que, rigorosamente falando, eles próprios não o possuíam. Dois deles, mais tarde, negaram tê-lo feito quando lhes lembrei o fato; o terceiro (o grande Charcot) provavelmente teria feito o mesmo se me tivesse sido dado vê-lo novamente. Mas essas três opiniões idênticas, que ouvia sem compreender, tinham 
ficado adormecidas em minha mente durante anos, até que um dia despertaram sob a forma de uma descoberta original. (FREUD, 1996a, p. 23).

Ao discutir essa "aprendizagem" freudiana, Voltolini (2006) argumenta: "Fato curioso ressaltado por Freud e que significa dizer que "é possível aprender alguma coisa de alguém que não tem a intenção de nos ensinar', de alguém que não sabe, rigorosamente falando, nem que está nos ensinando, nem o que está nos ensinando". O que importa, justamente, é a suposição de saber, a qual se ancora em um outro que possa sustentar nossas interrogações. Dito de outra forma, a construção do conhecimento explicita uma função transferencial.

O filósofo Gert Biesta (2018) argumenta que a educação tem que ser considerada como um risco, na medida em que não se caracteriza como um encontro pré-fixado. Esse autor também aponta que o ato educativo, que engaja alunos e professores, é marcado pela imprevisibilidade, apesar das tentativas administrativas dos chamados especialistas em educação, muitas vezes, negligenciarem esse elemento estrutural.

Enquanto os burocratas podem continuar tentando manter esse risco afastado no (equivocado) pressuposto de que a melhor educação é aquela que é completamente previsível, a educação como um empreendimento humano destinada à qualidade do crescimento de crianças e jovens nunca pode acabar como uma forma de gerenciamento e controle. Precisa, outrossim, de pessoas dispostas a assumir o risco, a arriscar-se a si mesmas para o futuro de modos humanos de existir juntas. (BIESTA, 2018, p. 29).

Se o ideal educativo de uma relação professor-aluno perfeita, sem obstáculos, e uma relação ensino-aprendizagem unívoca é sempre confrontado com a imprevisibilidade da transmissão, sempre equívoca, em tempos de educação à distância emergencial isso se torna ainda mais problemático. Interpelado pelo real representado por uma pandemia de proporções nunca esperadas nesses tempos pós-modernos, de busca incessante pelo gerenciamento, controle e previsibilidade, a tarefa docente percorre um caminho desconhecido e de destino incerto.

Amparado no ideal pedagógico hegemônico de totalidade, a inabilidade com as novas tecnologias e as constantes falhas de conexão com a internet são curiosamente traduzidas como “problemas de transmissão". Sim, há questões específicas da transmissão online que dificultam a comunicação, contudo, na perspectiva psicanalítica, a referida transmissão é de outra ordem, inconsciente, inapreensível. Voltolini (2001, 2007b) traz importantes apontamentos sobre a lógica da eficácia na qual a prática educativa está atualmente sustentada. No contexto da pandemia, isso se verifica na urgência das decisões que priorizam a continuidade da produtividade, afinal, "a educação não pode parar!”. Cássio e Carneiro (2020) alertam para o discurso gestor de tecnocratas, que tem interditado o debate da educação como direito e como bem público.

Em contraposição à pressa capitalista, fazse necessário as seguintes indagações: 0 que não pode parar? Qual é o objetivo da educação? Afinal, qual é o sentido de continuar a educar em tempos extraordinários?

Silva (2016), ao analisar a onipresença contemporânea do discurso tecno-científico do especialista, critica a ênfase demasiada nos aspectos metodológicos, que reduzem as preocupações educacionais a meras questões operacionais. Na atualidade da educação à distância emergencial, essa prioridade se exacerba ainda mais. Parece que todas as atenções estão voltadas ao conhecimento de novas tecnologias e metodologias compatíveis com o ciberespaço. Esse pragmatismo mascara uma pergunta anterior, muito mais fundamental, de acordo com essa autora, qual seja, em nome do que educar? No contexto específico deste trabalho, enfim, por que educar em tempos tão sombrios?

Alinhada à perspectiva arendtiana, Custódio (2011, p. 7), sublinha que o "mundo é, para a educação, o significado fundamental de seus esforços". Como bem sublinha Benvenuti (2013, p. 92), 
É pelo fato de não sermos apenas seres naturais, mas também mundanos - constituídos de toda a artificialidade daquilo que criamos, das heranças culturais que recebemos do passado, da relação com os objetos e espaços que nos cercam e entre nós - que a educação e a política existem.

A partir dessa perspectiva, é possível argumentar que devemos sim educar em tempos extraordinários de pandemia. Todavia, o que é necessário reivindicar é o acesso aos bens culturais públicos, ou seja, "conhecimentos, linguagens, expressões artísticas, práticas sociais e morais, enfim, o direito a um legado de realizações históricas às quais conferimos valor e das quais esperamos que as novas gerações se apoderem" (CARVALHO, 2004, p. 333).

Biesta (2012) destaca que a questão da finalidade deve sempre ter um lugar na discussão educacional. Ele critica o que tem nomeado como "learnification" da educação, ou seja, a ascensão e transformação de um vocabulário educacional em linguagem de aprendizagem. Segundo esse autor, aprendizagem é basicamente um conceito individualista, visto que se refere ao que as pessoas, como indivíduos, fazem. "Contrapõe-se assim, nitidamente, ao conceito de "educação", que sempre implica relação: alguém educando outra pessoa e a pessoa que educa tendo uma determinada noção de qual a finalidade de suas atividades" (BIESTA, 2012, p. 817).

A educação, na perspectiva de Biesta (2012), geralmente desempenha três funções diferentes, mas relacionadas, quais sejam: qualificação, socialização e subjetivação. Conhecimento, habilidades, disposições e formas de julgamento que permitem às crianças, jovens e adultos "fazer alguma coisa" têm relação com a função da qualificação. A socialização se caracteriza pelas variadas formas pelas quais nos tornamos membros e parte de ordens sociais, culturais e políticas, por meio da educação. A função de subjetivação é entendida como oposta à função de socialização, visto que "Não se trata precisamente da inserção de 'recém-chegados' às ordens existentes, mas das formas de ser que sugerem independência dessas ordens; formas de ser em que o indivíduo não é simplesmente um espécime de uma ordem mais abrangente" (BIESTA, 2012, p. 818-819).

Os filósofos Masschelein e Simons (2014) lembram que o significante escola, a partir da sua origem etimológica, scholé, significa tempo livre, ainda não determinado por demandas externas. Esses autores criticam a crescente transformação da escola em um lugar para trabalho e produção e argumentam que ela deveria ser protegida das demandas da sociedade para que fosse possível praticar e tentar coisas, sem o compromisso com a eficácia. Biesta e Picoli (2018, p. 22) apontam "uma tensão em seu [da escola] próprio tecido: uma tensão entre a necessidade de atender às demandas da sociedade e a necessidade de preservar-se destas". Estes autores advertem que "a voz de um dos mestres - sociedade - se tornou muito mais alta e muito mais dominante que a outra, a voz que diz que a escola também tem algo para fazer que não é automática ou necessariamente útil para a sociedade" (BIESTA; PICOLI, 2018, p. 22).

Em tempos de pandemia, qual função da educação, a partir das reflexões de Biesta (2015), deveria ser priorizada? Além das adequações metodológicas obrigatórias, devido à passagem do presencial ao remoto, não deveríamos debater acerca dos fins da educação? Estaríamos, novamente, privilegiando a técnica em vez das indagações éticas em torno da Educação? Tempos extraordinários, os quais rompem com o acelerado cotidiano, não seriam propícios à discussão coletiva no que concerne ao sentido da Educação? E a escola, fechada em tempos de distanciamento físico, continuará, pós-pandemia, a servir à sociedade? Não é tempo de discutirmos essas questões?

\section{Algumas (in)conclusões}

Na tradição psicanalítica, o conceito de a posteriori, après-coup, indica que o valor traumático de uma experiência não pode ser 
pensado em relação ao fato ocorrido, mas à lembrança elaborada ulteriormente. Ainda estamos no instante de ver a pandemia. É cedo para analisarmos as significações que serão construídas a respeito desse fenômeno global.

Este trabalho se insere na perspectiva do tempo de compreender, com todas as limitações de uma análise realizada no calor dos acontecimentos. Contudo, a magnitude da experiência coletiva exige, desde já, um trabalho de elaboração. Obedecendo aos preceitos psicanalíticos, não se trata de um trabalho prescritivo, em que professores, colocados em posição deficitária, encontrariam um manual de como agir e o que fazer, em tempos de pandemia. Trata-se, sim, de um convite à interrogação e à escansão da temática acerca da educação à distância emergencial.

Sem adotar um tom apocalíptico ou catastrófico, optou-se por delimitar alguns elementos estruturais concernentes ao tradicional trabalho docente presencial e discuti-los à luz das contingências que têm se apresentado durante a experiência de distanciamento físico e aulas remotas. Psic-análise se opõe à síntese e, exatamente por isso, novas indagações foram surgindo, à medida que a temática foi interrogada. Erotização da educação, função da escola, tradição e transmissão foram os desdobramentos possíveis na discussão a respeito do corpo, da presença e da temporalidade do trabalho docente.

0 momento atual coloca à mostra um impossível do ato educativo que se inscreve muito além da competência do professor e que está marcado por questões psíquicas e pedagógicas, mas também pelas questões históricas, tecnológicas, políticas e culturais que contornam o encontro docente-aluno. 0 ensino remoto, por mais promissor e resolutivo que possa ser nesse momento, representa apenas um dos elementos oferecidos pela escola, que é o conteúdo. Sabe-se, portanto, que a escola é muito mais que o conteúdo e a escolarização formal: é no encontro com o outro e nos afetos ali possíveis que o aluno se põe a produzir sentidos e movimentos no seu percurso pelo desejo de saber.

As três fontes de mal-estar, propostas por Freud (1976b), foram reatualizadas a partir da pandemia. A finitude do nosso corpo, as forças da natureza e nossas relações com os outros estão em pauta, absolutamente imbricadas. No que tange à Educação, é imprescindível considerá-la como um bem público, em que "A cria humana aprende fundamentalmente para participar de um mundo no qual ele 'é desejado e deseja' participar, e pela mesma razão ela às vezes não aprende o que se pretende que ela aprenda. De qualquer modo não é para a sobrevivência que se aprende, mas 'por amor"' (VOLTOLINI, 2007a, p. 137, grifo do autor). Mesmo em tempos tão disruptivos, é importante lembrar que aprendemos por amor!

Sem o momento de concluir, o qual seria apressado nas atuais circunstâncias, cabe lembrar que será necessária uma transição, nomeada como ensino híbrido, em que haverá a educação presencial e a educação à distância, de forma concomitante. Ainda há um longo percurso e muitas interrogações.

\section{REFERÊNCIAS}

ARENDT, H. A condição humana. Tradução: Roberto Raposo, posfácio de Celso Lafer. 10. ed. Rio de Janeiro: Forense Universitária, 2005.

ARENDT, H. Entre o passado e o futuro. Tradução: Mauro W. Barbosa. 6. ed. São Paulo: Perspectiva, 2009.

BAPTISTA, A.; JERUSALINSKY, J. (org.). Intoxicações eletrônicas: o sujeito na era das relações virtuais. Salvador: Ágalma, 2017.

BENVENUTI, E. A educação como âmbito prépolítico. In: COLÓQUIO INTERNACIONAL HANNAH ARENDT - A crise na educação revisitada, 1., 2013, São Paulo. Anais [...]. São Paulo: Feusp/Geepc, 2013. p. 80-94.

BIESTA, J. G. G. Boa educação na era da mensuração. Cadernos de Pesquisa, v. 42, n. 147, p. 808-825, set./dez. 2012.

BIESTA, G. J. J. Beautiful risk of education. London: Routledge, 2015. 
BIESTA, G.; PICOLI, B. O dever de resistir: sobre escolas, professores e sociedade. Educação, v. 41, n. 1, p. 21-29, 2018.

BRASIL. Ministério Público do Trabalho. Nota Técnica - GT COVID 19 - 11/2020, de 17 de julho de 2020. Dispõe sobre a atuação do Ministério Público do Trabalho na defesa da saúde e demais direitos fundamentais de professoras e professores quanto ao trabalho por meio de plataformas virtuais e/ou em home office durante o período da pandemia da doença infecciosa COVID-19. Brasília, DF, 2020. Disponível em: https://mpt.mp.br/pgt/noticias/ pgt-mpt-nota-tecnica-11-professores-as.pdf. Acesso em: 19 jul. 2020.

CARVALHO, J. S. F. de. "Democratização do ensino" revisitado. Educação e Pesquisa, São Paulo, v. 30, n. 2, p. 327-334, maio/ago. 2004.

CÁSSIO, F. L.; CARNEIRO, S. R. G. É hora de falar da educação como bem público. Le Monde Diplomatique Brasil, 20 mai. 2020.

CASTEL, R. Da indigência à exclusão, a desfiliação: precariedade do trabalho e vulnerabilidade relacional. In: LANCETTI, A. (org.). Grupos e coletivos. São Paulo: Hucitec, 1994. p. 21-48. (SaúdeLoucura, 4).

CUSTÓDIO, C. de O. Educação e mundo comum em Hannah Arendt: reflexões e relações em face da crise do mundo moderno. 2011. 134 f. Dissertação (Mestrado em Educação) - Faculdade de Educação, Universidade de São Paulo (USP), São Paulo, 2011.

FIGUEIREDO, L. C. As diversas faces do cuidar: considerações sobre a clínica e a cultura. In: MAIA, M. S. (org.). Por uma ética do cuidado. Rio de Janeiro: Garamond, 2009. p. 120-141.

FRANÇA FILHO, A. L.; ANTUNES, C. da F.; COUTO, M. A. C. Alguns apontamentos para uma crítica da EaD na educação brasileira em tempos de pandemia. Revista Tamoios, v. 16, n. 1, p. 16-31, 2020.

FRANCISCO, M. de F. S. Preservar e renovar o mundo. Revista Educação Especial: Biblioteca do Professor, São Paulo, n. 4, p. 26-35, 2007.

FREUD, S. Prefácio a Juventude Desorientada, de Aichhorn. In: FREUD, S. Edição Standard Brasileira das obras psicológicas completas de Sigmund Freud, vol. XIX. Rio de Janeiro: Imago, 1969a. p. 310-314.

FREUD, S. Três ensaios sobre a teoria da sexualidade. In: FREUD, S. Edição Standard Brasileira das obras psicológicas completas de Sigmund
Freud, vol. VII. Trad. J. Salomão. Rio de Janeiro: Imago, 1969b. p. 119-231.

FREUD, S. Algumas reflexões sobre a psicologia do escolar. In: FREUD, S. Edição Standard Brasileira das obras psicológicas completas de Sigmund Freud, vol. XIII. Trad. J. Salomão. Rio de Janeiro: Imago, 1976a. p. 285-288.

FREUD, S. 0 mal-estar na civilização. In: FREUD, S. Edição Standard Brasileira das obras psicológicas completas de Sigmund Freud, vol. XXI. Rio de Janeiro: Imago, 1976b. p. 75-174

FREUD, S. A História do movimento psicanalítico. In: FREUD, S. Edição Standard Brasileira das obras psicológicas completas de Sigmund Freud, vol. XIV. Rio de Janeiro: Imago, 1996a. p. 77-108.

FREUD, S. Luto e melancolia. In: FREUD, S. Edição Standard Brasileira das obras psicológicas completas de Sigmund Freud, vol. XIV. Rio de Janeiro: Imago, 1996b. p. 245-263

FUNDAÇÃO CARLOS CHAGAS. Educação escolar em tempos de pandemia na visão de professoras/ es da Educação Básica. Educação escolar em tempos de pandemia, Informe n. 1, São Paulo, 2020. Disponível em: https://www.fcc.org.br/fcc/ educacao-pesquisa/educacao-escolar-em-temposde-pandemia-informe-n-1. Acesso em: 19 jul. 2020.

KUPFER, M. C. M. O sujeito na psicanálise e na educação: bases para uma educação terapêutica. Educação \& Realidade, Porto Alegre, v. 35, n. 1, p. 265-28, jan./abr. 2010.

KUPFER, M. C. M.Etal.Valor preditivo de indicadores clínicos de risco para o desenvolvimento infantil: um estudo a partir da teoria psicanalítica. Latin American Journal of Fundamental Psychopathology Online, v. 6, n. 1, p. 48-68, 2009.

LACAN, J. O Seminário, livro 11. Os quatro conceitos fundamentais da psicanálise 1964. Rio de Janeiro: Zahar, 1979.

LAJONQUIÉRE, L. de. As palavras e as condições da educação escolar. Educação \& Realidade, Porto Alegre, v. 38, n. 2, p. 455-469, abr./jun. 2013.

LAJONQUIÈRE, L. de. Figuras do infantil. Petrópolis, RJ: Vozes, 2010.

MASSCHELEIN, J; SIMONS, M. Em defesa da escola: uma questão pública. 2. ed. Belo Horizonte: Autêntica, 2014.

ORGANIZAÇÃO DAS NAÇÕES UNIDAS PARA A EDUCAÇÃO, A CIÊNCIA E A CULTURA 
(UNESCO). Coalizão global de educação. 2020. Disponível em: https://pt.unesco.org/covid19/ educationresponse/globalcoalition. Acesso em: 16 mar. 2020.

RAHME, M. M. F. Psicanálise e Educação: um percurso de inquietações. Revista Espaço Acadêmico, v. 11, n. 131, p. 43-51, 2012.

SILVA, K. C. B. da. Educação inclusiva: para todos ou para cada um? Alguns paradoxos (in)convenientes. São Paulo: FAPESP/Escuta, 2016.

SILVA, K. C. B. da. O que uma mãe pode nos ensinar sobre função materna? Da face inexpressiva à construção do corpo erógeno. In: PARLATOOLIVEIRA, E.; SZEJER, M. (org.). 0 bebê e os desafios da cultura. São Paulo: Instituto Langage, 2019. p. 151-164.

SILVA, I. C. da. Da presença virtual: um estudo sobre a transferência em contexto de educação a distância. 2010. 132 f. Tese (Doutorado em Educação) - Faculdade de Educação, Universidade Federal do Rio Grande do Sul (UFRGS), Porto Alegre, 2010.

SOUZA, M. C. C. C. de. Sob o silêncio da escola, a memória. Revista Brasileira de História, v. 17, n. 33, p. 280-292, 1997.

VALENTE, J. A. O "estar junto virtual" como uma abordagem de educação a distância: sua gênese e aplicações na formação de educadores reflexivos. In: CARVALHO, M. J.; MENEZES, C.; NEVADO, R. (org.). Educação à distância: prática e formação do profissional reflexivo. São Paulo: Avercamp, 2009. p. 37-64.

VIRILIO, P. 0 espaço crítico. Rio de Janeiro: Editora 34, 1993.
VOLTOLINI, R. Do contrato pedagógico ao ato analítico: contribuições à discussão da questão do mal-estar na educação. Estilos da Clínica, São Paulo, v. 6, n. 10, p. 101-111, 2001.

VOLTOLINI, R. A educação como "fato inconveniente" para a psicanálise. In: PSICANÁLISE, EDUCAÇ̃̃o E TRANSMISSÃO, 6., 2006, São Paulo. Anais eletrônicos [...]. São Paulo: LEPSI/IP/FE/USP, 2006. Disponível em: http://www.proceedings.scielo. $\mathrm{br} /$ scielo.php?script=sci_arttext\&pid=MSC00000 $00032006000100006 \& \operatorname{lng}=$ pt\&nrm=abn. Acesso em: 17 mar. 2020.

VOLTOLINI, R. A relação professor-aluno não existe: corpo e imagem, presença e distância. ETD-Educação Temática Digital, v. 8, n. esp., p. 119-139, 2007a.

VOLTOLINI, R. O discurso do capitalista, a psicanálise e a educação. In: LEITE, N. V. de A.; AIRES, S.; VERAS, V. (org.). Linguagem e gozo. Campinas, SP: Mercado de Letras, 2007b. p. 197-212.

VOLTOLINI, R. Uma pedagogia esquecida do amor. ETD-Educação Temática Digital, v. 21, n. 2, p. 363-381, 2019.

VOLTOLINI, R. Educação e Psicanálise. Rio de Janeiro: Zahar, 2011.

XIMENES, S. B. Et al. A discriminação no ensino nãopresencial em tempos de pandemia. Nexo, 16 jun. 2020. Disponível em: https://nexojornal.com.br/ ensaio/debate/2020/A-discriminação-no-ensinonão-presencial-em-tempos-de-pandemia. Acesso em: 16 mar. 2020.

Recebido em:24/07/2020 Aprovado em 09/12/2020

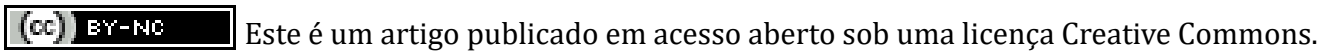

